Volume 14, número 1, ano, 2018.

\title{
REFLEXÕES SOBRE OS PRINCÍPIOS EDUCATIVOS DOS MOVIMENTOS SOCIAIS E A EDUCAÇÃO DO CAMPO
}

\author{
Wender Faleiro ${ }^{1}$ \\ Magno Nunes Farias ${ }^{2}$
}

\begin{abstract}
RESUMO A Educação do Campo nasce a partir dos Movimentos Sociais do Campo. Partindo disso, esse trabalho busca trazer reflexões acerca dos Princípios Educativos dos Movimentos Sociais do Campo, afim de expor a importância desses princípios nos processos de institucionalização da Educação do Campo enquanto política pública. Nota-se assim, que materializar esses princípios é um processo fundamental para que a Educação do Campo como política contribua para a transformação e justiça social no campo brasileiro.

Palavras-Chave: Movimentos sociais. Educação do campo. Princípio educativo.
\end{abstract}

\section{REFLECTIONS ON THE EDUCATIONAL PRINCIPLES OF SOCIAL MOVEMENTS AND THE FIELD EDUCATION}

\begin{abstract}
The Field Education originates from the social movements of the field. Assuming that, this paper seeks to bring reflections about the Educations Principles of Social Movements, in order to expose the importance of these principles in the process of institutionalization of the Field Education as public policy. It has noted that the materialization of these principles is a fundamental process for Field Education as policy which contributes to the transformation and social justice in the Brazilian field.
\end{abstract}

Keywords: Social movements. Field education. Educational principle.

\section{INTRODUÇÃO}

A Educação do Campo nasce a partir dos Movimentos Sociais do Campo, tendo um forte protagonismo do Movimento dos Trabalhadores Sem Terra (MST), porém, com intensas ações de outros atores como, Movimento de Mulheres Camponesas, Movimento dos Atingidos por Barragem, Movimento dos Pequenos Agricultores, Movimento Camponês Popular, entre outros. Sendo assim, seus princípios fundamentais estão estreitamente vinculados com a cultura, os valores, as formas de organização coletiva, as reivindicações e aos demais processos de luta e resistência desses Movimentos Sociais. Partindo desse lugar, busca-se aqui construir uma reflexão acerca dessas articulações, focando principalmente nos princípios educativos dos Movimentos Sociais, e como esses podem contribuir para a consolidação da Educação do Campo enquanto política pública.

\footnotetext{
${ }^{1}$ Doutor em Educação pela Universidade Federal de Uberlândia, Docente na Universidade Federal de Goiás/ Regional Catalão.

${ }^{2}$ Terapeuta Ocupacional pela Universidade de Brasília, Mestrando em Educação pela Universidade Federal de Goiás/ Regional Catalão.
} 
Volume 14, número 1, ano, 2018.

\subsection{Educação do Campo e Movimentos Sociais do Campo}

A Educação do Campo se consolida como um processo sócio-político cultural, que surge a partir das pressões dos Movimentos Sociais formados pelas trabalhadoras e trabalhadores do campo, que vem lutando por direitos sociais, tendo como parâmetro um desenvolvimento societário voltado para a emancipação, incluindo a luta por uma educação transformadora das realidades do território camponês brasileiro (CALDART, 2012).

Assim, os protagonistas do Movimento de Educação do Campo ${ }^{3}$ são os trabalhadores, que atuam em prol de políticas voltadas para o fortalecimento da classe camponesa. Esses Movimentos são formados por assentados, acampados, assalariados rurais, ribeirinhos, comunidades tradicionais, das florestas e águas, atingidos por barragem, quilombolas, indígenas e demais sujeitos e coletivos, que marcam a construção de um percurso de luta e resistência que se opõe ao processo de expropriação, exploração e expulsão compulsória do campesinato, lutando pelo direito à terra e as demais condições materiais e imateriais de existência (HAGE, 2014). As contradições dos modelos hegemônicos socioeconômicos que ameaçam os modos de vida no campo brasileiro são fatos geradores dessa movimentação, onde os atores coletivos lançam mão de ações reivindicando direitos a partir de suas necessidades sociais, para que reconheçam a existência do campesinato, seus modos de vida, cultura, lutas e resistências e historicidade.

A luta pela Educação do Campo se inicia principalmente pelo MST, a partir da década de 1980, e vai se consolidando pela década de 1990 e no século XX, quando se potencializa enquanto Movimento de Educação do Campo. Inicialmente esse processo ocorre pela intensificação das ações dos grupos sociais como atores fortes, devido ao fim da ditadura militar e pelos avanços Legais, como a Constituição Federal de 1988 e a Lei de Diretrizes e Bases da Educação Nacional de 1996 (Lei no 9.394, de 20 de dezembro de 1996), o que fortaleceu ainda mais as ações dos Movimentos Sociais para terem seus direitos reconhecidos. Um evento essencial para o surgimento desse processo foi o I Encontro de Educadores e Educadoras da Reforma Agrária, em 1997, outro evento importante foi a I Conferência Nacional Por uma Educação Básica do Campo, em 1998, fundamental para a construção da Articulação

\footnotetext{
${ }^{3}$ Utiliza-se aqui a nomenclatura Movimento de Educação do Campo, pois entende-se esse processo como Movimento mais amplo, pelo fato da Educação do Campo não ter como foco apenas a luta pela educação, mas ser um fenômeno de dimensão educacional, política, social, cultural e econômica que almeja consolidar um projeto de campo e de sociedade emancipatório.
} 
Volume 14, número 1, ano, 2018.

Nacional Por uma Educação do Campo. Depois desse evento essa Articulação Nacional promoveu diversos eventos: Seminário Nacional Por uma Educação do Campo (2002) e a II Conferência Nacional Por uma Educação do Campo (2004), entre outras ações de dimensão nacional, estadual e municipal (OLIVEIRA; CAMPOS, 2012).

Partindo desses contextos a Educação do Campo começa a ser pensada em um percurso tridimensional entre o Campo, a Política Pública e a Educação, que objetiva materializá-la enquanto uma política pública voltada para a classe trabalhadora, contribuindo assim, como política, para um desenvolvimento camponês e de sociedade mais justa, porém, não se desvinculando de seu papel que "implica na formação dos trabalhadores para lutas anti-capitalistas, necessárias à sua própria sobrevivência: como classe, mas também como humanidade" (CALDART, 2008, p. 72).

É necessário afirmar que esse Movimento é muito mais amplo, não se reduz a políticas públicas, mas essa é uma das suas finalidades, sendo necessário sempre colocar os atores camponeses como protagonistas para construir esses percursos políticos, como sujeito de ação e direito. Assim, a institucionalização da Educação do Campo é fundamental para sua consolidação com política pública de direitos de todos os sujeitos do campo, seja na Educação Básica ou no Ensino Superior. Contudo, esse movimento não é simples, tendo em vista que as políticas públicas estão em espaços com ideologias burocráticas, instituídas e com lógicas em prol da classe dominante.

A partir das discussões iniciais notamos que a construção da Educação do Campo está estreitamente relacionada com a luta dos Movimentos Sociais, ela é fruto dessa luta e resistência dos trabalhadores e trabalhadoras em superar lógicas educacionais de exclusão e interiorização, concepções urbanocentradas, adestradoras, que negavam a existência desses sujeitos em seus modos de existir. Assim, há a necessidade desse processo se consolidar enquanto política pública articuladas com os Movimentos Sociais do campo. A pergunta central posta aqui é: Quais são os princípios educativos dos Movimentos Sociais, e de que forma se dá a relação desses princípios no processo de consolidação da Educação do Campo enquanto política pública?

\section{METODOLOGIA}

Trata-se de um estudo descritivo-exploratório, de caráter qualitativo, busca realizar uma reflexão a partir de uma revisão bibliográfica. O método qualitativo é utilizado 
Volume 14, número 1, ano, 2018.

quando se conceber um olhar para as questões subjetivas e objetivas do mundo, que não podem ser enumeradas. Se caracteriza como descritivo-exploratório pelo fato do estudo descrever questões sobre o tema estudado, com objetivo de ampliar as possibilidades de reflexão e, assim, explorar mais as questões, deixando-as mais explícitas para a construção de hipóteses e possibilidades inovadoras (SILVEIRA; CÓRDOVA, 2009).

Nesse sentido, aqui vamos sistematizar de maneira mais concreta como os princípios educativos desses movimentos se consolidam em direção à formação humana dos sujeitos do campo, e como isso desemboca na Educação do Campo (sendo este um Movimento Social multifacetado), buscando como na literatura trazem os princípios educativos dos Movimentos Sociais, afim de realizar uma reflexão sobre a importância desses na consolidação da Educação do Campo enquanto política pública.

\section{RESULTADOS E DISCUSSÃO}

\subsection{Princípios Educativos dos Movimentos Sociais}

Aqui vamos destrinchar sobre os princípios educativos dos Movimentos Sociais, ora nas especificidades dos Movimentos do Campo, ora de modo geral. Para isso vamos utilizar como base três autores que se debruçam sobre esse objeto: Arroyo (2003; 2009), Caldart (2004; 2001) e Gohn (2011).

Arroyo (2009) pontua que discorrer sobre os aspectos que envolvem conhecimento, pedagogias, bem como os princípios educativos das ações de grupos que são organizadas ou não em Movimento Social é fundamental para reconhecer que esses coletivos produzem experiências. Coletivos esses constituídos por grupos historicamente segregados e oprimidos em diferentes dimensões, seja econômica, política e cultural, mas que não se caracterizam pela passividade ou conformismo, pelo contrário, se organizam e promovem ações de luta e resistência se opondo a essas dinâmicas opressoras e se reafirmando como sujeitos sociais, políticos e culturais, como os Movimentos Sociais do Campo.

Há a existência de uma construção hegemônica que desenvolve padrões de saber, cognitivos, sociais, éticos, raciais, culturais e de gênero que tendem a constituir categorias de sujeitos, no qual os que não estão dentro desses padrões são considerados irracionais, incultos, primitivos, inferiores, ignorantes, sem saberes e conhecimentos (ARROYO, 2009). Nessa perceptiva, historicamente se pensou os sujeitos do campo em lugares de inferioridade, como 
Volume 14, número 1, ano, 2018.

os Outros, que dificilmente alcança o lugar de "civilizado e racional" do padrão hegemônico e dominante.

Essa concepção se instaura como movimento político e social de dominação e subordinação, em que esses sujeitos vivenciam um processo de negação de suas existências são desumanizados. Assim, a população do campo é concebida como esses Outros, oprimidos economicamente, política, social e culturalmente, com concepções dominantes que legitimam seus lugares de inexistente, de apenas mão de obra que devem se sujeitar a relações de exploração e expropriação (ARROYO, 2009).

Os estudos pós-coloniais tem[sic] destacado que o poder sobre os Outros se conformou sobre um saber sobre esses Outros. Pensados como objetos naturais, em estado de natureza, primitivos, selvagens, o poder-saber poderia submetê-los ou ignorá-los como inexistentes, inferiores, pré-humanos. O pensamento que se conformou sobre eles e que os conformou como Outros passou a ser usado como um dos instrumentos de legitimação da relação política de dominação-subordinação. Constituiu-se e persiste como justificativa de sua inferiorização (ARROYO, 2009, $\mathrm{s} / \mathrm{p})$

Nessa lógica os processos sócio-educativos e políticos tenderam a legitimarem essas ideologias colonizadoras de pensar esses sujeitos, as replicando nos sistemas de educação pública Sendo assim, essa perspectiva concebe uma educação que inferioriza os saberes dos Outros, os povos do campo, colocando a educação "hegemônica" como a única saída desses passarem da irracionalidade para a racionalidade. "Esses pensamentos sobre os Outros [...] persiste nas formas de pensar as crianças e adolescentes e seus coletivos [...] do campo. Persiste como os pensamentos que os configura" (ARROYO, 2009, s/p). Assim, Santos (2010) aponta a construção de um pensamento abissal ${ }^{4}$ que coloca esses processos de inferiorização como inatos nos processos civilizatórios políticos, socioeconômicos e pedagógicos.

Nessa relação o Nós (cujo residem os padrões hegemônicos de existência, civilização e poder, vinculados com relações de produção capitalista) se afirmam como o

\footnotetext{
4 "O pensamento moderno ocidental é um pensamento abissal. Consiste num sistema de distinções visíveis e invisíveis, sendo que as invisíveis fundamentam as visíveis. As distinções invisíveis são estabelecidas através de linhas radicais que dividem a realidade social em dois universos distintos: o universo 'deste lado da linha' e o universo 'do outro lado da linha'. A divisão é tal que 'o outro lado da linha' desaparece enquanto realidade, torna-se inexistente, e é mesmo produzido como inexistente. Inexistência significa não existir sob qualquer forma de ser relevante ou compreensível. Tudo aquilo que é produzido como inexistente é excluído de forma radical porque permanece exterior ao universo que a própria concepção aceite de inclusão considera como sendo o Outro" (SANTOS, 2010, p. 23-24).
} 
Volume 14, número 1, ano, 2018.

padrão adequado de existir, sobrando para os Outros a não existência e impossibilidade de emancipação e coprodução nos espaços de direito.

Os territórios dos Outros vão se conformando em loteamentos clandestinos, ocupações, amontoados humanos sem esgotos, sem água, sem luz, sem direito ao espaço, sem transporte, sem serviços públicos (ARROYO, 2009, s/p).

Nesse percurso de contradições que tendem a negar os direitos de diversos sujeitos, entre eles os povos do campo, os conferindo situações que precarizam suas formas de existir, há diversas mobilizações desses sujeitos, que se organizam em coletivos e Movimentos Sociais que lutam por formas de humanização e emancipação (ARROYO, 2003).

Dentro desse contexto, os Movimentos Sociais nas suas diversas ações vêm rompendo esses pensamentos que os colocam como inferiores, produzindo movimentos revolucionários, se colocando como co-presentes nos espaços de produção de conhecimento e de pesquisa, contestando as formas de pensa-los como os Outros, instituindo seus modos de vida como legítimos, conscientes, políticos, culturais e racionais.

Nessa presença afirmativa nos espaços de produção do conhecimento e especificamente de produção das teorias e pedagogias sócio-educativas repolitizam o papel que tiveram e continuam tendo na sua produção histórica como Outros. Mas também mostram que esse pensamento, essas teorias e pedagogias trazem as marcas conformantes que persistem das formas de pensá-los como inferiores no pólo [sic] negativo para trazê-los para o pólo [sic] positivo. Ao pensar assim os Outros, o pensamento se pensou, as teorias e pedagogias sócio-educativas se pensaram e conformaram a si mesmas com a função civilizatória, conscientizadora, libertadora, educativa. Na medida em que os Outros desconstroem as imagens em que foram pensados abrem o caminho para reconformar o próprio campo do conhecimento e das tórias e pedagogias sócioe-ducativas que se configuraram nessa forma de pensálos e de pensar-se. Uma contribuição de extrema relevância trazida pelas ações e presenças afirmativas dos coletivos: para repensar-se as teorias e pedagogias sócioeducativas dos Outros terão que repensar as formas como tem sido pensados os Outros, os diversos e os diferentes em classe, raça, etnia, gênero, campo, periferia (ARROYO, 2009, s/p).

Ocorre um tensionamento contra-hegemônico dos pensamentos abissais que legitimam a inexistência dos povos do campo como sujeitos de conhecimento, há um movimento de reconhecimento dos valores, culturais, saberes como mulheres e homens que possuem um modo de pensar legítimo. Arroyo (2009) aponta que há o desenvolvimento de apropriação dos padrões de poder e saber, fazendo com que suas ações repolitizem esses padrões de conhecimento.

Dessa maneira, supera-se os processos de que conceberam suas existências como negativa, e "ao despojo de seu lugar na história da produção cultural e intelectual" (ARROYO, 2009, s/p). Assim, eles defendem condições e direitos para existirem, com 
Volume 14, número 1, ano, 2018.

projetos de campo, de sociedade e universidade, com base na reforma agrária, com seus saberes, modos de pensar, percursos históricos de luta e resistência, seus modos de produzir, suas políticas, desenvolvendo contribuição para a produção cultural, intelectual e principalmente a fim de realizar movimento de transformação e emancipação da classe trabalhadora do campo brasileiro.

Dentro desses processos dos Movimentos Sociais do Campo há de se compreender seus princípios educativos, partindo da compreensão de como esses Movimentos são contestadores da consciência social, e assim "reeducam o pensamento educacional" (ARROYO, 2003, p. 30). Além disso, é preciso compreender dentro dessas dimensões formativas "que a formação humana é inseparável da produção mais básica da existência, do trabalho, das lutas por condições materiais de moradia, saúde, terra, transporte, por tempos e espaços de cuidado, de alimentação, de segurança" (Ibidem, p. 31).

Nesse sentido, é necessário olhar as dimensões educativas e formadoras, entendendo como se fazem necessárias suas contribuições para os processos educativos e teorias pedagógicas, compreendendo como esses Movimentos Sociais podem contribuir para que a práxis educativa dos sujeitos sociais. Em princípio o aprendizado dos direitos é um dos aspectos mais essenciais, contribuindo para que os sujeitos tomem consciência sobre seus direitos à escola, à terra, ao conhecimento, potencializando suas lutas por condições dignas de existência e humanização de seus modos de vida.

Esses atores coletivos lançam mão de ações pedagógicas pautadas nas condições concretas e históricas das vidas do campo, dentro das contradições socioeconômicas e culturais que tendem a dificultar a copresença e coprodução dos camponeses nos espaços de produção de saber e poder (ARROYO, 2003).

\footnotetext{
Os movimentos sociais em suas ações coletivas apontam para outras pedagogias politicamente mais radicalizadas. De um lado, apontam para a desconstrução do pensamento abissal, sacrificial ao afirmar-se sujeitos políticos, de cultura, de saberes, de racionalidades (ARROYO, 2009, s/p).
}

Portanto, os princípios educativos se consolidam a partir dessa reafirmação como sujeitos que existem e são multidimensionais. Os Movimentos Sociais pautam suas ações a partir da totalidade dos sujeitos, por exemplo, o educando nessa perspectiva é visto não apensas na sua dimensão de aluno, em processo de escolarização, mas como sujeito cultural, educativo, territorial, afetivo e social, que está tencionando pelas relações de produção capitalista que precarizam a vida no campo. 
Volume 14, número 1, ano, 2018.

Dessa forma, os Movimentos questionam os padrões sócio-econômicas, e principalmente culturais, tendo em vista que esses colocam a cultura como uma dimensão essencial de formação. Para se compreender os processos dão uma perspectiva macro e microssocial, eles então ressignificam os processos de forma a se empoderar e conscientizar como atores sociais de direito. Arroyo (2003, p. 42) aponta que esses

[...] atores sociais reinterpretam normas, valores, lógicas, saberes, padrões culturais. Criam novos significados. Tensões que estão no cerne das sociedades contemporâneas onde a construção de identidades grupos se defronta com a impositiva identidade social global.

Os Movimentos Sociais do campo constituem suas próprias maneiras de conceber a realidade, bem como os fatos que envolvem a Questão Agrária, educação, modo de olhar para a escola. Traçando estratégias de enfrentamento pedagogias que os colocam no lugar e inexistente e legitimação sobre suas formas de existir, como agentes protagonistas (ARROYO, 2003). Se contrapondo assim aos pensamentos conformadores, "trazem para o pensamento sócio-educativo e político desestabilizações que o obrigam” o instituído a refletir sobre as visões de inferiorização dos sujeitos oprimidos (ARROYO, 2009, s/p).

\footnotetext{
A novidade das virtualidades pedagógicas das ações coletivas que vêm do lado de lá é que se contrapõem radicalmente às dicotomias, às linhas abissais que os jogaram no lado de lá como sem-lei, sem-conhecimento, sem validade, sem existência, semhumanidade e por isso sem-território, sem-terra, sem-espaço, sem-vida, sem cultura. Falta à teoria pedagógica crítica, progressista reconhecer essas pedagogias, explicitar seus significados político-pedagógicos (ARROYO, 2009, s/p).
}

Dentro dessas dimensões Caldart (2001) reflete sobre os princípios educativos dos Movimentos Sociais do Campo, tendo como base o Movimento dos Trabalhadores Sem Terra (MST), tendo em vista que os percursos desse Movimento têm se destacado e se consolidado no cenário brasileiro em um breve período de tempo (desde 1984), marcando um caminho de diversas conquistas, dando lugar à existência de vida nesses lugares. Para a autora, o MST se caracteriza principalmente pelas suas estratégias de ocupação, pelas suas lutas combinadas com as lutas pela terra, como, por exemplo, pela educação do campo, saúde, culturas, direitos humanos, pela forma de sua organização, e pela sua "capacidade que vem construindo de universalizar, ou de tornar a sociedade como um todo, uma bandeira de luta que nasce de um grupo social específico e de seus interesses sociais imediatos” (Ibidem, p. 209, grifos da autora). Nesse sentido a autora destrincha sobre uma Pedagogia do Movimento Sem Terra.

Assim, ao pensar sobre as práticas educativas e suas contradições sociais que geram processos dualistas, ou seja, de exclusão de maiorias no Estado brasileiro, é 
Volume 14, número 1, ano, 2018.

fundamental direcionar um olhar para esses Movimentos Sociais do Campo, pois esses se caracterizam como sujeitos de resistência.

E, além disso, "estes sujeitos e suas lutas nos ensinam algo mais sobre processos de transformação social, e sobre práticas de educação a eles vinculadas" (Ibidem, p. 209). Desta maneira, a autora expõe a necessidade de olhar os movimentos como sujeitos pedagógicos, sendo a pedagogia "aqui entendida como teoria e prática da formação humana" (CALDART, 2004, p. 315), objetivando refletir sobre suas contribuições para uma educação menos reprodutivista de desigualdades sociais. Tendo em vista que o MST tem um papel de formação de sujeitos, pois, além de possibilitar a democratização de terras, contribui para a constituição dos seres humanos em processos de luta, sabendo-se que lutar também é educarse, já que essa luta busca transformar as realidades sociais.

Caldart (2004; 2001) aponta que a luta se caracteriza como a principal característica de formação humana dos sujeitos Sem Terra, fazendo com que essas vidas entrem em movimento e tencionem o que está posto, ou seja, os modos de vida capitalista e seus aspectos ideológicos e culturais enraizados com hegemônicos. Esse aspecto se assemelha ao que é posto por Arroyo (2009), pois esses Movimentos de luta "cotidiana está a marca da atitude de pressionar as circunstâncias para que elas sejam diferentes do que são" (CALDART, 2004, p.331, grifos da autora), assim, se pressiona o instituído, desestabilizam o contraditório em prol de processos que geram mais justiça social/coletivo.

Além disso, os processos pedagógicos que constituem esses sujeitos, conseguem gerar processos transformadores para que esses compreendam os sentidos das lutas, esses sujeitos conseguem assim se abrirem para as transformações de si mesmo, os empoderando com a possibilidade de transpor o que está formatado, para que assim seja possível construir uma sociedade em novas perspectivas.

Acima de tudo, esses sujeitos compartilham de valores coletivos e sociais, que confrontam os valores colocados como ideais dentro dos processos de produção capitalista (individualismo, competitividade), gerando assim movimentos emancipatórios e humanizadores, que concebem a existência de homens, mulheres e crianças em uma perspectiva de consciência de classe trabalhadora. Caldart (2004) pontua a forma de organização coletiva com um dos princípios educativos do MST, tendo em vista que fazer parte desse Movimento já se consolida como de constituição contra-hegemônica. A autora aponta que essa organização coletiva se consolida como princípio pelo fato de 
Volume 14, número 1, ano, 2018.

[...] ser o enraizamento uma condição para que aconteça a formação humana, então ele próprio deve ser considerado o processo educativo fundamental [, tendo em vista que a maioria dos sujeitos que estão ali] foram sendo progressivamente desenraizadas, principalmente por terem sido expulsas da terra, mas também por um conjunto todo de processo de exclusão social (Ibidem, p. 343, grifos da autora).

Esse princípio é fundamental tendo em vista que esses sujeitos começam a ter uma nova raiz, fazendo daquele espaço uma possiblidade de formação, crescimento e florescimento, firmado em uma base concreta que acolhe suas angustias, lutas e resistências, esse movimento instaura a construção de uma identidade coletiva, e ao mesmo tempo o individual possui seu lugar (CALDART, 2004; 2001).

Caldart (2004), em plena afinidade com as ideias de Arroyo (2003; 2009), aponta como matrizes pedagógicas a pedagogia da cultura e a pedagogia da história que carregam a formação desses Movimentos. A pedagogia da cultura se consolida sob o aspecto que o Movimentos Sociais educa-se "cultivando o modo de vida produzido pelo Movimento" (Ibidem, p. 360, grifos da autora). Esse modo de ser se consolida pelo Movimento de luta, pelas relações com a terra, com a própria organização coletiva, ou seja, uma diversidade de ações, valores, experiências, signos e saberes que consolidam e embasam o aspecto cultural que caracteriza esses sujeitos, consolidando um modo de existir "que vincula cultura com produção material da existência" (Ibidem, p. 361).

Ainda sobre a questão cultural, Caldart (2004) utiliza como referência Williams (1936), o autor distingue o marcador da coletividade que caracteriza a cultura do trabalhador, a qual constitui os Movimentos Sociais, se opondo a cultura burguesa individualista, dicotomias que desembocam também na oposição sobre projetos societários.

Já sobre o princípio que se consolida como pedagogia da história discorre sobre a perspectiva que no Movimento educa-se "cultivando sua memória e compreendendo a história" (Ibidem, p. 370). Essa perspectiva está estritamente relacionada com os aspectos culturais, mas que deve ser frisada por ser concebida como um aspecto fundamental. Isso se contrapõe a uma oposição a pedagogia capitalista que se propõe a instituir um processo educativo voltado diretamente para o presente, tendo em vista que os resgates históricos podem levar ao resgate de lições revolucionárias, fazendo com que seja questionado o presente posto.

Assim, o Movimento coloca que o "saber-se enraizado em um passado significa ter mais força; na verdade é condição para pretender algum tipo de transformação" (Ibidem, p. $372)$. 
Volume 14, número 1, ano, 2018.

Para finalizar, Gohn (2011) faz um resgate de modo mais generalizado sobre os princípios educativos dos Movimentos Sociais, colocando que processo de "aprendizagem no interior de um movimento social, durante e depois de uma luta, são múltiplas, tanto para o grupo como para indivíduos isolados" (Ibidem, p. 352). De maneira mais sistemática pontua essas questões em doze (12) tipos de aprendizagem, que estão em articulação dos aspectos já discutidos até aqui. Essas aprendizagens são:

- Aprendizagem prática: nas perspectivas da forma da organização, das estratégias de articulação e participação.

- Aprendizagem teórica: compreendo a partir dos conceitos que mobilizam esses Movimentos, como a coletividade, cultura, história, identidade, empoderamento, bem como observar como materializá-las nas ações concretas.

- Aprendizagem técnica instrumental: apreender os modos de funcionamento de questões mais burocráticas, sobre aspectos legais.

- Aprendizagem política: tomada de consciência como sujeitos de direitos, sobre as relações de poder instituídas pelo Estado, e os desafios em materializar reinvindicações pautadas na justiça social, há um movimento de politização.

- Aprendizagem cultural: compreender os modos de vida que identifica o Movimento, os tencionamentos culturais, e os aspectos instituídos no modo de fazer política burguês. Além de aspectos relacionados a reconhecimento da diversidade cultural.

- Aprendizagem linguística: consolidação de uma linguagem que torne possível articulações coesas para compreender os aspectos que os rodeiam, criam estratégias (gramática, símbolos) próprias para isso.

- Aprendizagem sobre a economia: noções relacionadas ao custo e estratégias de economia nos processos de produção.

- Aprendizagem simbólica: compreender aspectos sobre suas representações e como se autorrepresentam, refletindo sobre os significados dessas questões. Objetivando ressignificar conteúdos que os marginalizam.

- Aprendizagem social: questões relacionadas ao comportamento de grupos, formas de se colocar no discurso e ouvir.

- Aprendizagem cognitiva: aprender conteúdos, questões e informações a partir da integração com outros sujeitos em eventos. 
Volume 14, número 1, ano, 2018.

- Aprendizagem reflexiva: exercitar o pensar, reflexão sobre as ações praticadas, desembocando em seus potenciais com fonte de saberes.

-Aprendizagem ética: a partir da vivência com outros sujeitos que integram o movimento, com base em valores de coletividade, solidariedade, democracia, que consolidam uma rede ética e política sólida (GOHN, 2011).

Logo, os Movimentos Sociais, dentre eles o do campo, se conformam como fontes produtivas de saberes que contribuem para a reflexão de novas noções sobre os processos educativos brasileiros. Como campo de diversas ações, tendem a dar vida a processos mais criativos e geradores de transformações efetivamente políticas e sociais (GOHN, 2011).

\subsection{Entrelaçamento entre Princípios Educativos e Educação do Campo enquanto política pública}

Os Movimentos Sociais do Campo possuem diversos princípios educativos, como são postos pelos autores, suas indagações partem de diversos pressupostos, que por vezes se aproximam e acabam por gerar reflexões comuns, apontando os Movimentos como fonte de concepções contra-hegemônicas de formação de sujeitos e fonte inesgotável de saberes. Posto isso, temos um desafio maior, que é materializar esses princípios nos cotidianos da Educação do Campo nos processos de institucionalização (na Educação Básica e no Ensino Superior) como política pública.

A Educação do Campo prevê um processo de institucionalização estreitamente vinculado com os Movimentos Sociais, em plena articulação com os trabalhadores e trabalhadoras do campo, tendo em vista que a Educação do Campo em ambientes institucionais deve estar vinculada com um processo de sociedade cultivado por esses sujeitos, objetivando uma formação crítica e emancipatória, tendo em vistas os processos de inferiorização e exclusão (MOLINA, 2015). Assim, a educação do campo se consolida na luta pelo acesso à terra, ao trabalho desalienado, à democratização e valorização cultural, a relações de produção pautadas na agricultura familiar camponesa (CALDART, 2009).

O vínculo de origem da Educação do campo é com os trabalhadores 'pobres do campo', trabalhadores sem-terra, sem trabalho, mas primeiro com aqueles já dispostos a reagir, a lutar, a se organizar contra 'o estado da coisa', para aos poucos buscar ampliar o olhar para o conjunto dos trabalhadores do campo (CALDART, 2009, p. 41). 
Volume 14, número 1, ano, 2018.

Porém, Molina (2010) vem apontando preocupações sobre seu sentido originário no processo de institucionalização governamental, tendo em vista seu papel em ser "ação educativa no sentido da contra-hegemonia, capaz de contribuir para a promoção de profundas transformações na sociedade brasileira" (Ibidem, p. 137). Ademais, é posto que há uma mudança que vem ocorrendo

[...] no conceito Educação do Campo, a partir de sua incorporação à agenda governamental, especialmente no âmbito das Secretarias Estaduais e Municipais de Educação, e as mudanças no protagonismo dos Movimentos Sociais no cenário de construção e execução dessas Políticas Públicas (MOLINA, 2010, p. 137).

A partir da própria conjunturaneoliberal, com a potencialização do capitalismo em se organizar a partir de novos moldes, o processo da Educação do Campo se torna ameaçado no âmbito das políticas públicas efetivamente para classe trabalhadora do campo. Há uma incorporação da Educação do Campo na agenda estatal, porém, muitas vezes, se dá pelo esvaziamento do verdadeiro caráter desse projeto educativo e social, buscando moldá-la a uma política enquadrada nos modelos do Estado burguês. Pois, para se "falar de Políticas Públicas significa termos presente as questões das estruturas de poder e de dominação, dos conflitos, das disputas entre direitos, necessidades, carências e privilégios” (Ibidem, p. 144), que tenha como protagonistas os Movimentos Sociais, se essas políticas forem protagonizadas pela classe dominante não carregarão esses critérios, tendo uma desvinculação das propostas da Educação do Campo.

Além disso, Molina (2015), partindo de uma reflexão sobre as Licenciaturas em Educação do Campo, frisa o receio das propostas da Educação do Campo serem sufocadas pelos processos instituídos, se tornando mais um movimento que contribui para a mercantilização da produção de conhecimento, presente principalmente na Educação Superior. Tendo em vista que, histórica e atualmente, os processos políticos têm contribuído para instituir uma pedagogia capitalista, que tende atender aos interesses de acumulação de capital - estreitamente vinculada com o agronegócio.

Nesse sentido Caldart (2009) aponta que os Movimentos Sociais não podem recuar nos processos, pressionando o Estado a conceber políticas públicas realmente articuladas com seus interesses fundamentais. Tendo em vista, que mesmo a não conciliação com esses Estado burguês, há a necessidade de o fazer garantir uma a Educação do Campo com um direito de todos, e sem perder o "horizonte maior de transformação estrutural, de 
Volume 14, número 1, ano, 2018.

superação do modo de produção capitalista e da barbárie social que lhe é inerente, sem se deixar imobilizar no momento presente" (MOLINA, 2010, p. 144)

Tendo em vista a fragilidade e da estrutura governamental e estatal em construir políticas específicas para o campo, pois essas "sempre estiveram de maçanetas trancadas (para constituir tais políticas), ao se abrirem, continuam, em grande medida, com as dobradiças emperradas" (MUNARIN, 2006, p. 16), na medida em que as concepções de educação para o campo historicamente residem na educação rural, como uma extensão menos prioritária da educação urbana. A autora aponta que existem diversas barreiras para tais ações, como empecilhos burocráticos, leis autoritárias, funcionários com concepções ultrapassadas e reducionistas, ausência de sujeitos com formação adequada. Temos que observar as aberturam estatais, como a construção da Coordenação-Geral de Educação do Campo na estrutura do Ministério da Educação, que está sendo desmontada atualmente com o processo do golpe político em curso, foi apenas um "ponto de partida", tendo em vista que ainda existe uma longa trilha a ser explorada até chegarmos nos moldes ideais para as políticas educacionais do campo.

Dentro dessas concepções, existe justamente a impossibilidade de instituirmos as políticas públicas de Educação do Campo nos diversos serviços educacionais sem instituir olhar e materializar os princípios educativos dos Movimentos Sociais do Campo nos currículos desses espaços, partindo do princípio que a Educação do Campo só se materializa com seu princípio originário se estiver em articulação com os Movimentos (ARROYO, 2015). Nesse sentido o Arroyo (2015, p. 48) afirma que a Educação do Campo "não se efetivará enquanto não se avançar na construção de Currículos que traduzam as concepções, os conhecimentos, as culturas e valores de que são produtores e sujeitos os movimentos sociais". Partindo desse pressuposto infere-se que formatação dessa educação contra-hegemônica só se efetivará enquanto proposta quando se materializar dentro do instituído, ou seja, quando o instituinte virar instituído.

O currículo não se configura apenas enquanto instrumento que direciona as práticas dos docentes e discentes, mas ele concebe questões de valores, direito, cultura, conhecimento e política, ou seja, concepções de sujeitos e mundo que perpassam ambiente de educação. Assim, esse se coloca como instrumentos fundamentais nas concepções de cultura e conhecimento, que direciona transformações em âmbito institucional, tendo que incorporar as contribuições do Movimento Sociais, sendo necessário “abri-los a que conhecimentos, 
Volume 14, número 1, ano, 2018.

culturas, valores que vem sendo produzidos pelos movimentos sociais do campo" (ARROYO, 2015, p. 49). E assim, transpor as grades que ainda tornam esses currículos fixos, sem perspectivas de mudanças a partir dos Movimentos Sociais. Nesse sentido, os princípios educativos podem contribuir modificando as relações de poder e saber, reproduzindo no sistema escolar e universitário, o movimento de luta por direito exige currículos estreitamente relacionados com esses percursos históricos, culturais e políticos.

Para a Educação do Campo de materializar enquanto política pública sem perder seus vínculos com os Movimentos Sociais, é necessário que sejam construídas de forma aberta a movimentos de mudança, mas que principalmente garantam o direito dos sujeitos do campo

[...] aos conhecimentos produzidos pela diversidade de movimentos sociais na diversidade de formas de produção, trabalho e resistências; currículos que reconheçam e fortaleçam a diversidade de culturas, memórias, identidades e universos simbólicos dos educandos; que garantam, ainda, o saber de si como sujeitos produtores de conhecimentos, culturas, valores e história; que coloquem em diálogos horizontais esses saberes com o conhecimento produzido pela humanidade (ARROYO, 2015, p. 47).

Além disso, é necessário ultrapassar concepções políticas educacionais que colocam a adaptação como uma estratégia para pensar a educação para o território camponês, tendo suas políticas pensadas apenas nas adaptadas para a realidade camponesa (ARROYO, 2007). Deve-se assim, superar visões generalistas de direitos e cidadania, que ignoram a heterogeneidade da vida do campo, sem reconhecimento das diferenças, que pedem políticas públicas construídas a partir das necessidades sociais territoriais. Assim, deve-se pensar nos sujeitos em suas historicidade e concretudes, tendo os Movimentos fundamental importância para rever essas contradições, bem como estabelecer seus princípios educativos como norteadores de novas políticas publica focalizadas nas dinâmicas sociais dos sujeitos do campo.

\section{CONSIDERAÇÕES FINAIS}

Os princípios educativos dos Movimentos Sociais do Campo estão postos dentro da literatura, e, acima de tudo, estão em pleno movimento nos territórios de luta e resistência. Sendo agora o desafio é materializá-los dentro dos processos institucionais, buscando fixar uma correlação de forças afim de superar um Estado que tende a firmar políticas desalinhadas com as necessidades sociais das classes trabalhadoras do campo. 
Volume 14, número 1, ano, 2018.

Observa-se que as reflexões realizadas nesse estudo demonstram que os princípios educativos dos Movimentos Sociais são potentes e determinantes para a execução da Educação do Campo enquanto política pública, para não se perder a radicalidade desse Movimento educativo, político, cultural e social.

Nesse sentido, os princípios trazem a originalidade e radicalidade da Educação do Campo, tendo em vista que os Movimentos Sociais do Campo são os protagonistas que dão vida a esse fenômeno a partir da realidade concreta desse território, sendo essencial serem colocados como atores fundamentais em todos os espaços que se propõem a executar uma Educação do Campo coerente e transformadora, principalmente no terreno das políticas públicas, pois se encontram dentro de uma dinâmica de Estado Capitalista que tende a assimilar as propostas da classe trabalhadora de forma enviesada em prol do capital. Dessa forma, trabalhar e potencializar os princípios educativos é ser mais vigilante as manipulações e contradições do capitalismo para a Educação do Campo, é afirma sua visceralidade enquanto projeto de emancipação, para a transformação do status quo. É determinante para superar perspectivas capitalistas, neoliberais, teorias socioeducativas e pedagógicas hegemonias que inferiorizam e subalternizam o campo.

Os Movimentos Sociais representam atores coletivos que lutam diretamente pelos seus direitos territoriais, sociais, epistemológicos, culturais e de produção, suas experiências se fundam na superação do pensamento abissal (SANTOS, 2010), que os colocam como Outros, invisíveis, inexistentes e inferiores. "O conhecimento e o direito modernos representam as manifestações mais bem conseguidas do pensamento abissal" (SANTOS, 2010, p. 24), dentro disso há as dicotomias entre os saberes legítimos e ilegítimos, entre o domínio do direito e do não-direitos, de acordo com os critérios abissais da ciência e direito hegemônico (que classificam e distinguem os sujeitos), que subordinaram e ainda subordinam sujeitos do campo. Contudo, os Movimentos Sociais passam a desestabilizar esses critérios abissais, exigindo justiça social na produção do direito e de conhecimento, produzindo experiências, epistemologias, pedagogias e práxis educativas transgressoras, e que necessitam serem aprofundadas para a consolidação da Educação do Campo.

Portanto, deve-se resgatar os princípios educativos desses Movimentos, materializar seus aspectos enquanto organização coletiva, historicidade, valorização da cultura, formação crítica e emancipatória, só assim a Educação do Campo se tornará uma política pública que atingirá sua finalidade, desalienada e desvinculada qualquer formar de 
Volume 14, número 1, ano, 2018.

aprisionamento, pelo contrário, empoderando os sujeitos com agentes capazes de transpor o que está posto como hegemônico.

\section{REFERÊNCIAS}

ARROYO, M. G. Pedagogias em movimento - o que temos a aprender dos Movimentos Sociais?. Currículo sem Fronteiras, v.3, n.1, pp. 28-49, Jan/Jun 2003.

Políticas de Formação de Educadores (as) Do Campo. Cad. Cedes, Campinas, vol. 27, n. 72, p. 157-176, maio/ago. 2007.

Ações Coletivas e Conhecimento: Outras Pedagogias? In.: Universidade

Popular dos Movimentos Sociais, 2009. Disponível em: < http://www.universidadepopular.org/site/pages/pt/documentos/leituras/leituras-sobre-aupms.php>. Acesso em: 01 de junho de 2016.

Os Movimentos Sociais e a construção de outros currículos. Educar em Revista, Curitiba, Brasil, n. 55, p. 47-68, jan./mar. 2015.

CALDART, R.S. Pedagogia do Movimentos Sem Terra. Editora Expressão Popular, 2004.

O MST e a formação dos sem terra: o movimento social como princípio educativo. Estudos Avançados 15 (43), 2001.

Educação do Campo. In: CALDART, Roseli et al. (org.). Dicionário da Educação do Campo. Rio de Janeiro: Escola Politécnica de Saúde Joaquim Venâncio, Expressão Popular, 2012, p. 257-265.

Sobre educação do campo. In: SANTOS, Clarice Aparecida dos (Org.). Educação do campo: campo - políticas públicas - educação. (NEAD Especial: 10). Brasília: INCRA; MDA, 2008. p. 67-97

EDUCAÇÃO DO CAMPO: NOTAS PARA UMA ANÁLISE DE PERCURSO. Trab. Educ. Saúde, Rio de Janeiro, v. 7 n. 1, p. 35-64,mar./jun.2009.

GOHN, M. da G. Movimentos sociais na contemporaneidade. Revista Brasileira de Educação v. 16 n. 47 maio-ago. 2011.

HAGE, S.M. Movimentos sociais do campo e educação: referências para análise de políticas públicas de educação superior. Revista Eletrônica de Educação, v. 8, n. 1, p.133-150, 2014.

MOLINA, M.C. Reflexões sobre o significado do protagonismo dos Movimentos Sociais na construção de Políticas Públicas de Educação do Campo. In.: MOLINA, M. C (Org.). Educação do Campo e Pesquisa II: questões para reflexão. - Brasília: MDA/MEC, 2010.

Expansão das licenciaturas em Educação do Campo: desafios e potencialidades. Educar em Revista, Curitiba, Brasil, n. 55, p. 145-166, jan./mar. 2015. 
Volume 14, número 1, ano, 2018.

MUNARIM, A. Elementos para uma política pública de Educação do Campo. In.: MOLINA, M. C. Brasil. Ministério do Desenvolvimento Agrário. Educação do Campo e Pesquisa: questões para reflexão. - Brasília: Ministério do Desenvolvimento Agrário, 2006.

OLIVEIRA, L. M. T e CAMPOS, M. Educação básica do campo. In: CALDART, Roseli et al.(org.). Dicionário da Educação do Campo. Rio de Janeiro: Escola Politécnica de Saúde Joaquim Venâncio, Expressão Popular, 2012, p. 237-250

SANTOS, B. S. Para além do pensamento abissal: das linhas globais a uma ecologia de saberes. In: SANTOS, B. S.; MENEZES, M. (Orgs.). Epistemologias do Sul. São Paulo: Cortez, 2010

SILVEIRA, D.T.; CÓRDOVA, F. P. Unidade 2 - A Pesquisa Científica. In: GERHARDT, T.E. e SILVEIRA, D. T. Métodos de pesquisa. Coordenado pela Universidade Aberta do Brasil - UAB/UFRGS e pelo Curso de Graduação Tecnológica - Planejamento e Gestão para o Desenvolvimento Rural da SEAD/UFRGS. - Porto Alegre: Editora da UFRGS, 2009. 